\title{
Novel fractal antenna for UWB applications using the coplanar waveguide feed line
}

\author{
Akram El Hamdouni' ${ }^{1}$, Abdelali Tajmouati ${ }^{2}$, Jamal Zbito $^{3}$, Abdelwahed Tribak ${ }^{4}$, Mohamed Latrach ${ }^{5}$ \\ 1,2,3 LMEET Laboratory of Faculty of Sciences and Techniques Settat, Hassan $1^{\text {st }}$ University, Morocco \\ ${ }^{4}$ Institut National of Postes and Telecommunication Rabat, Morocco \\ ${ }^{5}$ Microwave Group ESEO Angers, France
}

\begin{tabular}{l} 
Article Info \\
\hline Article history: \\
Received May 2, 2018 \\
Revised Mar 14, 2019 \\
Accepted Apr 3, 2019 \\
\hline Keywords: \\
Coefficient of reflection \\
Radiation pattern \\
CPW \\
FCC \\
UWB
\end{tabular}

\section{Corresponding Author:}

Akram El Hamdouni,

LMEET Laboratory of Faculty of Sciences and Techniques Settat,

Hassan $1^{\text {st }}$ University,

Route de Casablanca Km 3,5 BP 539, Morocco.

Email: akram.elhamdouni@yahoo.fr

\begin{abstract}
In this study an original Coplanar Waveguide (CPW) antenna has been achieved into simulation and manufacturing in order to be an important candidate for the Ultra-wideband applications. The area of the proposed structure is $34 \mathrm{mmx} 43 \mathrm{~mm}$ operating in the frequency range $3.1-10.6 \mathrm{GHz}$ released as UWB by the Federal Communications Commission (FCC). To perform the design of the proposed CPW antenna two electromagnetic solvers has been adopted which are CST of Microwave Studio and ADS of Agilent. The radiating patch has been chosen circular with fractal geometry based on circular slots with different sizes. The dielectric substrate is an Epoxy FR4 with a Relative permittivity 4.4, a thickness 1.6 and a loss tangent 0.025 . To valid the functionality of the antenna two parameters has been computed which are the coefficient of reflection and the radiation pattern and confirmed into measurement by using the Network Analyser and the anechoic chamber.
\end{abstract}

Copyright $(0) 2019$ Institute of Advanced Engineering and Science. All rights reserved.

\section{INTRODUCTION}

The microstrip line, based on the transmission line connected to the radiating patch and the ground plane in the bottom of the dielectric substrate, remains the most popular technique to design the antennas operating in the lower and little higher frequencies. The microstrip antenna consists of the focus of the maximum energy in the strip line on the top of the substrate and the virtual conductor created by the ground plane which defines the main electromagnetic radiation. However, the integration of the microstrip antenna in the circuits presents some difficulties related to the ground plane inaccessibility and the difficulty to establish the shunt between the strip line and the ground [1-4].

The coplanar waveguide (CPW) has been invented to avoid the disadvantages of the microstrip by designing the various conductors in the same geometric plane, in order to have the dielectric substrate without any conductor. The first coplanar strip structure has been developed by Seymour Cohn in the 1969s. Over the recent years others structures more developed has been involved in the conception of the antenna due to several advantages such as the low cost of manufacturing, the reduced dispersion, the decreased losses related the radiation and the ease ground plane existing in the same side with the transmission line [5-10]. 


\section{ANTENNA GEOMETRY}

The CPW antenna depicted in this study has been chosen with a circular radiating patch connected to a strip line established between two partial ground planes on the top of the dielectric substrate. The fractal geometry applied on the radiator, is based on a circular shape with different diameters respectively from the higher to the lower are D1, D2 and D3 as shown in Figure 1.

The substrate used to design the proposed antenna is an Epoxy FR4 characterized by the below features:

a. Substrate thickness: $\mathrm{h}=1.6 \mathrm{~mm}$.

b. Relative dielectric permittivity $\varepsilon r=4.4$.

c. Dielectric loss: $\tan (\delta)=0.025$.

d. Metallic thickness: $\mathrm{t}=35 \mu \mathrm{m}$.

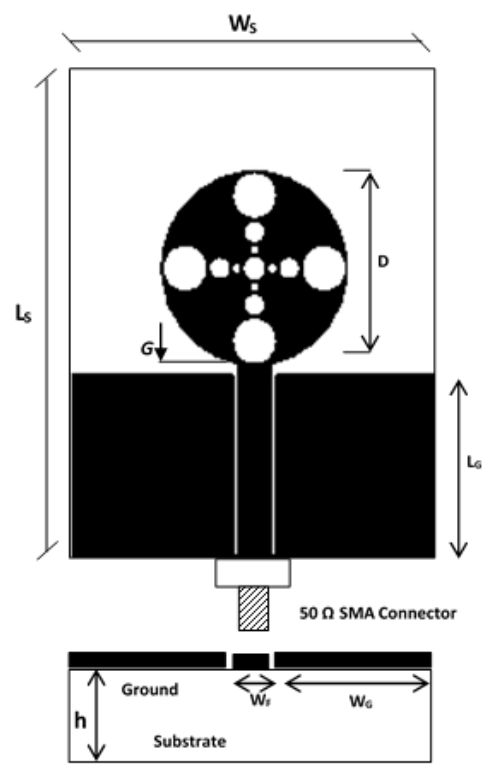

Figure 1 . The Geometry of the validated antenna

The different values of the optimized parameters of the simulated antenna have been summarized in the Table 1.

Table 1. Calculated and validated dimensions of the designed antenna

\begin{tabular}{cc}
\hline Parameter & Value $(\mathrm{mm})$ \\
\hline $\mathrm{W}_{\mathrm{S}}$ & 34 \\
$\mathrm{~L}_{\mathrm{S}}$ & 43 \\
$\mathrm{~W}_{\mathrm{G}}$ & 15 \\
$\mathrm{~L}_{\mathrm{G}}$ & 16 \\
$\mathrm{~W}_{\mathrm{F}}$ & 3 \\
$\mathrm{G}$ & 1 \\
$\mathrm{D}$ & 17 \\
$\mathrm{D}_{1}$ & 4.05 \\
$\mathrm{D}_{2}$ & 1.925 \\
$\mathrm{D}_{3}$ & 0.8625 \\
\hline
\end{tabular}

\section{ANTENNA DESIGN}

The main electromagnetic solver used to design the proposed antenna was CST of Microwave Studio by using it component Transient based on the numerical method called finite-difference time domain (FDTD). Three parameters have been generated by CST which are the coefficient of reflection, the gain and the radiation pattern in order to have a complete idea about the antenna behaviour in the FCC band. The second solver was ADS of Agilent developed by using the Method of Moment (MoM) which is involved to double check the $S_{11}$ parameter and compared with the graph generated by CST [11-14]. 
The coefficient of reflection computed by CST and ADS shown the Figure 2 presents a good matching in terms of input impedance at $50 \Omega$ in the frequency range $3.1 \mathrm{GHz}-10.6 \mathrm{GHz}$, with the values of $S_{11}$ less than $-10 \mathrm{~dB}$ in the UWB. The gain of the antenna has been simulated by using CST in the Figure 3 in the frequency $2 \mathrm{GHz}-12 \mathrm{GHz}$ which include the FCC band chosen in this study. According to the graph the gain is between $2 \mathrm{~dB}$ and $3 \mathrm{~dB}$ in the lower frequencies which mean that the CPW antenna can be used in indoor applications in UWB, however the gain reaches the value between $4 \mathrm{~dB}$ and $6 \mathrm{~dB}$ in higher frequencies in this case the proposed antenna can be a good candidate for outdoor application in the FCC band.

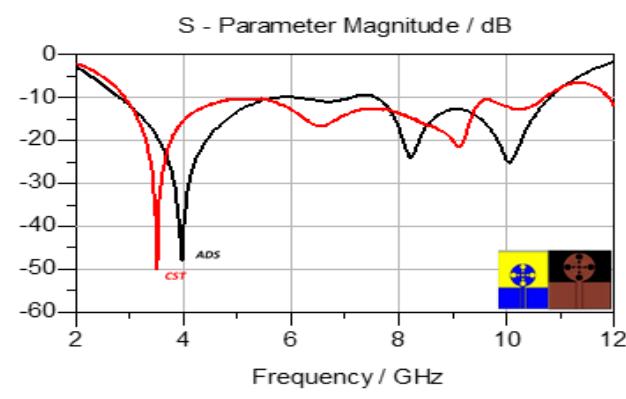

Figure 2. $S_{11}$ vs frequency of the designed CPW antenna

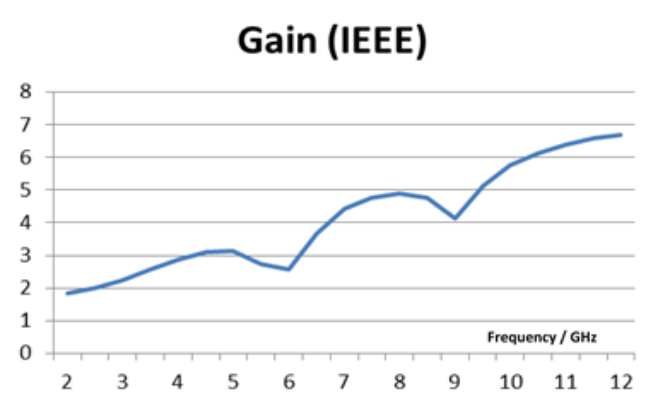

Figure 3. Gain vs frequency of the designed CPW antenna

The radiation pattern in the frequencies $3 \mathrm{GHz}, 5 \mathrm{GHz}, 7 \mathrm{GHz}$ and $10 \mathrm{GHz}$ has been simulated by CST in E-plane and H-plane shown in the Figure 4 (a), (b), (c) and (d). The diagram of radiation is unidirectional in H-plane in different frequencies with some slight variation in higher frequencies such as $10 \mathrm{GHz}$. While in E-plane the radiation pattern keep the directionality behaviour in all frequencies. The graph of $S_{11}$ it's not a sufficient parameter to conclude that the antenna will radiate even the input impedance matching, because the antenna can be analogue to pure resistance, so the radiation pattern is mandatory criteria to confirm the radiation od the antenna.

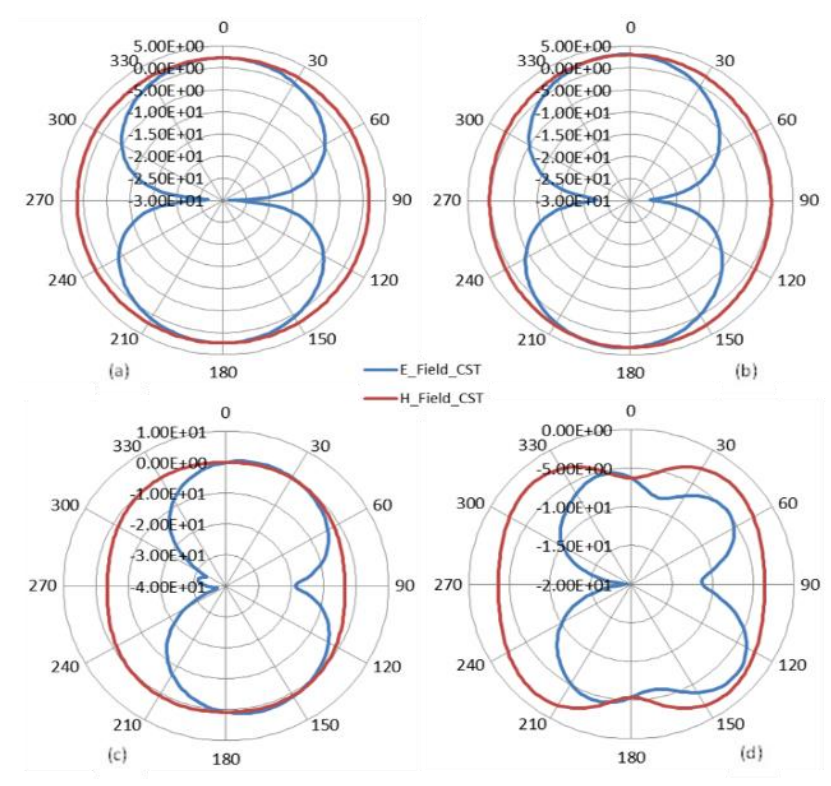

Figure 4. The Radiation Pattern in E-Plane and H-Plane by CST; (a)@3GHz, (b)@5GHz, (c)@7GHz and (d)@10GHz

\section{EXPERIMENTAL RESULTS AND DISCUSSION}

The photolithographic method has been used to fabricate the antenna, in order to perform the measurement series based on the Network Analyser and the Anechoic chamber, the Figure 5 present the manufactured antenna. The PNA-X Network Analyzer N5247A from Agilent Technologies coefficient 
has been used to measure the coefficient of reflection. The Figure 6 presents the two graphs of $\mathrm{S}_{11}$ generated by ADS and CST and the one validated into measurement. A good agreement in terms of form and matching of input impedance at $50 \Omega$ has been confirmed. The Figure 6 presents the two graphs of $S_{11}$ generated by ADS and CST and the one validated into measurement. A good agreement in terms of form and matching of input impedance at $50 \Omega$ has been confirmed.

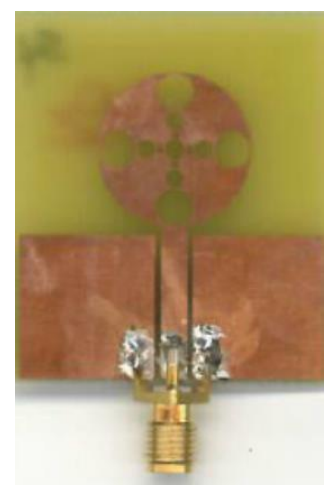

Figure 5. The fabricated antenna

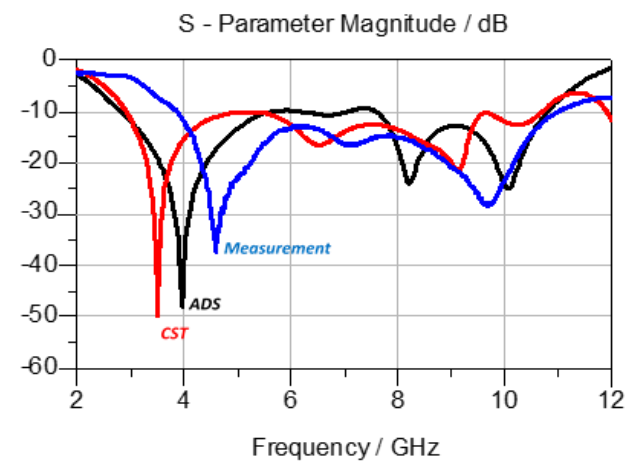

Figure 6. $\mathrm{S}_{11}$ vs frequency into simulation and measurement

The radiation pattern has been measured in H-plane only in the four frequencies $3 \mathrm{GHz}, 5 \mathrm{GHz}$, $7 \mathrm{GHz}$ and $10 \mathrm{GHz}$ shown in the Figure 7 with the simulated diagrams by CST also in H-Plane. The radiation pattern of the proposed antenna has been performed by establishing a Microwave link of $3 \mathrm{~m}$ inside the anechoic chamber to avoid the diffraction of the electromagnetic waves. The transmitter antenna is an horn with known output power and gain. So to calculate the gain of the proposed antenna in $360^{\circ}$ it was necessary to use the link budget formula, with the receive level measured by the Network analyser and the software ANT-32 Analysis. According to the diagram of radiation an agreement between the simulated and measured graphs in terms of radiation behaviour which unidirectional in all the frequencies chosen the coverage the FCC band.

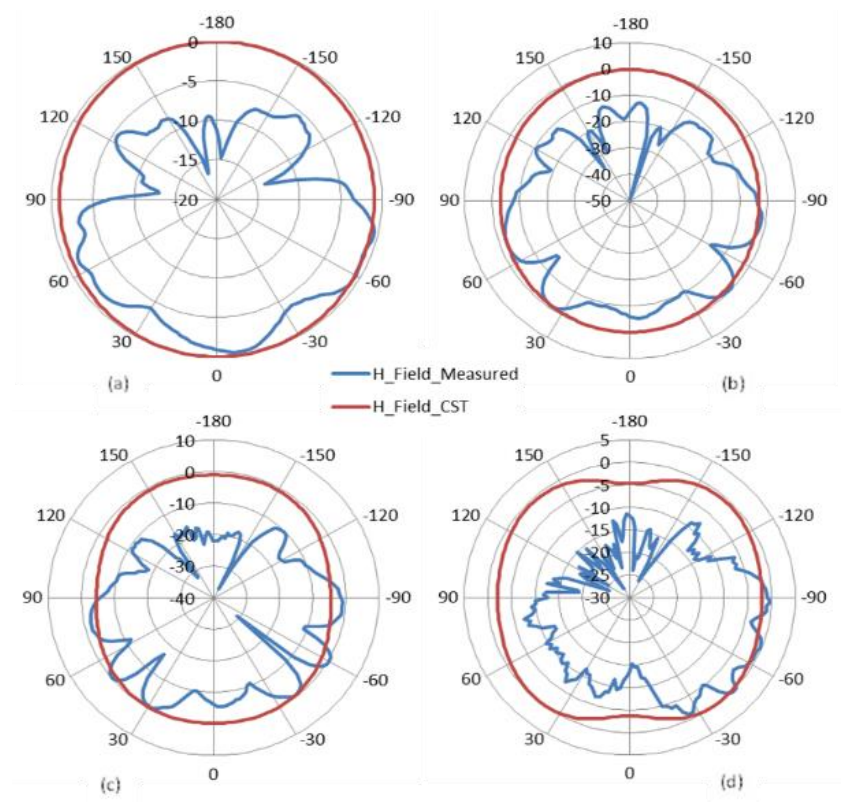

Figure 7. The Radiation Pattern in H-Plane by CST and into Measurement; (a) @3GHz, (b) @5GHz, (c)@7GHz and (d)@10GHz 


\section{CONCLUSION}

The achieved CPW antenna into simulation and measurement in order to operate in the frequency range $3.1 \mathrm{GHz}-10.6 \mathrm{GHz}$ with a fractal radiating patch, can be used as good candidate for UWB applications in outdoor and indoor due to several features related to the CPW technique and the parameters of the antenna itself. The proposed structure can be considered as original antenna with low cost, ease of fabrication and facility of integration with MMICs. The coefficient of reflection measured and computed is matched in terms of input impedance at $50 \Omega$, the radiation pattern is unidirectional in all frequencies of the FCC band. The gain subdivide the operational frequency range to two bands according to its value, in the lower frequencies the antenna can be operating in indoor UWB applications while in the higher frequencies the antenna can be used in the outdoor circuits.

\section{REFERENCES}

[1] S.Natarajamani, S. Kumar Behera, S. Kumar Patra, "Planar UWB Fractal Antenna with Band-Notched Characteristic," International Conference on Electronic Systems (ICES-2011), 7-9 Jan 2011, NIT Rourkela, India, p. 290, 2011.

[2] P. Felber, Fractal Antennas, "A literature study as a project for ECE 576 Illinois Institute of Technology December 12,” 2000 (Revised: January 16, 2001), p. 5, 2001.

[3] R. Kumar,D. Magar, K. Kailas Sawan, "On the design of inscribed triangle circular fractal antenna for UWB applications," International Journal of Electronics and Communications (AË̈) Accepted, p. 68, 10 May 2011.

[4] G. M. Yang, R. H. Jin, G. B. Xiao, C. Vittoria, V. G. Harris, and N. X. Sun, "Ultra-wideband (UWB) Antennas With Multiresonant Split-Ring Loops," IEEE Transactions On Antennas And Propagation, Vol. 57, No. 1, p. 256, January 2009.

[5] G. M. Yang, R. H. Jin, G. B. Xiao, C. Vittoria, V. G. Harris, and N. X. Sun, "Ultrawideband (UWB) Antennas With Multiresonant Split-Ring Loops," IEEE Transactions On Antennas And Propagation, Vol. 57, No. 1, p. 256, January 2009.

[6] N.M. Sahar, M.T. Islam and N. Misran, "Analysis of Fractal Antenna for Ultra-Wideband Application," Research Journal of Applied Sciences, Engineering and Technology 7(10): 2022-2026, 2014.

[7] R. L. Yadava, M. Ram and S. Das, "Multiband Triangular Fractal Antenna for Mobile Communications," R L Yadav et. al. / International Journal of Engineering Science and Technology, Vol. 2(11), 6335-6348, 2010.

[8] M. Levy, Student member, IEEE, D. Sriram Kumar, Anh Dinh, "A Novel Fractal Uwb Antenna For Earthquake And Tsunami Predictionapplication (LETPA)," 2013 26th IEEE Canadian Conference of Electrical And Computer Engineering (CCECE), 2013.

[9] R.Kumar and K. K. Sawant, "Design of CPW -Fed Fourth Iterative UWB Fractal Antenna," International Journal of Microwave and Optical Technology, Vol.5, No.6, November 2010.

[10] R. Kumar, "Ultra-Wide Band Antenna for Biological Applications," Int. J. of Recent Trends in Engineering and Technology, Vol. 4, No. 3, Nov 2010.

[11] B. Rama Rao, S.Alekhya and Dr. P.V. Sridevi, "Design of Circular with triangle Microstrip Fractal Antenna for Dual band and UWB applications," International Journal of Scientific \& Engineering Research, Volume 4, Issue 7, July-2013.

[12] R.Kumar, Sheetal Gaikwad and M. Tech, "On the Design of Nano-arm Fractal Antenna for UWB Wireless Applications," Journal of Microwaves, Optoelectronics and Electromagnetic Applications, Vol. 12, No. 1, June 2013.

[13] R. Ghatak, B. Biswas2, A. Karmakar and Dipak R. Poddar, "A Circular Fractal Uwb Antenna Based On Descartes Circle Theorem With Band Rejection Capability," Progress In Electromagnetics Research C, Vol. 37, 235-248, 2013.

[14] Dhrgham. K. Naji, Jaber. S. Aziz and Raad S. Fyath, "Design and Simulation of RFID Aperture Coupled Fractal Antennas," Originally published in the International Journal of Radio Frequency Identification \& Wireless Sensor Networks, ISSN 1847-9812, vol. 4, 25:2012.

\section{BIOGRAPHIES OF AUTHORS}

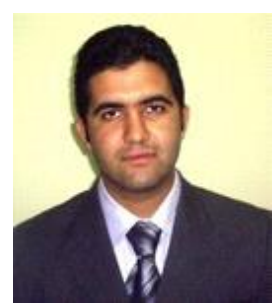

Akram El Hamdouni was bornin Safi, Morocco, in 5 Febraury 1982. He received the Ingeneer degree in telecommunications engineering fromthe Institut of postes and Telecomunications (INPT), Rabat, Morocco, in 2006, the Master degree from the Faculty of Sciences and Techniques of Marrakech of the University Cadi Ayyad, in 2004. AcctuallyPh.D. Studientthe LMEET Laboratoryof Mecanic, Énergétic, Electronic et Telecommunications of Faculty of Sciences and Techniques of Settat, of University Hassa $1^{\text {st }}$. 


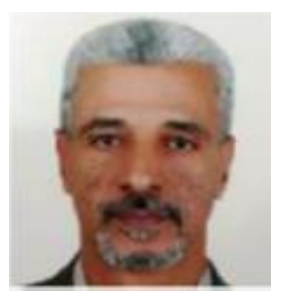

Abdelali Tajmouati was born in, Morocco, in 1962. He received the Ph.D. degree in science engineering from the University of Perpignan, France, in 1992. He is currently an associate Professor of Electronics, thermal transfer and termodynamic in faculty of sciences and techniques University Hassan 1st, Settat,, Morocco. He is involved in the design of hybrid, monolithic active and passive microwave electronic circuits.

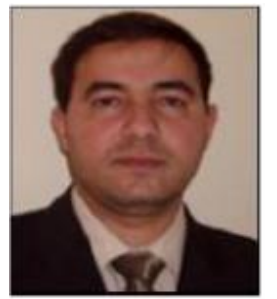

Jamal Zbitou was born in Fes, Morocco, in June 1976. He received the Ph.D. degree in Electronics from the University of Nantes, Nantes, France, in 2005. He is currently a Professor of Electronics in the Faculty of Sciences and Techniques, University Hassan 1st in Settat, Morocco. He is involved in the design of hybrid, monolithic active and passive microwave electronic circuits.

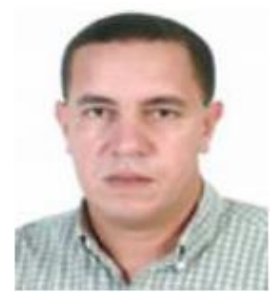

Ahmed Errkik was born in July 1960 in Morocco. He received the Ph.D. degree in physics from the University of Technology Compiègne (UTC), Compiègne, France. He is currently an associate Professor of physics in FST University Hassan 1st, Settat, Morocco, and he is the head of the laboratory LMEET. He is involved in the design of hybrid, monolithic active and passive microwave electronic circuits.

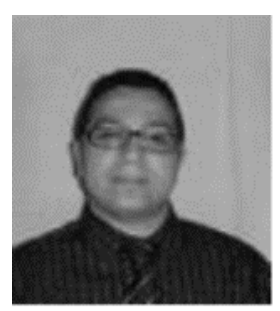

Abdelwahed Tribak was born in Larache, Morocco, in 1981. He received the M.Sc. degree in physics from Abdelmalek Essaadi University, Tétouan, Morocco, in 2006. He received a Master degree in communications engineering from the University of Cantabria, Santander, Spain, in 2008, and received the $\mathrm{PhD}$ of Telecommunication degree in 2011, from the University of Cantabria, Santander, Spain. Since 2006 to 2011, he has been with the Department of Communications Engineering, University of Cantabria. Since 2011 he is a Professor in the National Institute of Poste and Telecommunication, Rabat, Morocco. His main area of activities is microwave circuits and systems; antenna feed subsystems for satellite and radio-astronomy applications.

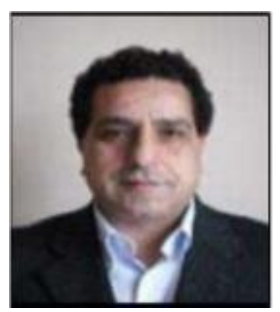

Mohamed Latrach was born in DouarKsiba, Sless, Morocco, in 1958. He received the Ph.D. degree in Electronics from the University of Limoges, Limoges, France, in 1990. He is currently a Professor of microwave engineering with the EcoleSuprieured'Electronique de l'Ouest (ESEO), Angers, France, where his research involves RF and microwaves. His field of interest is the design of hybrid, monolithic active, and passive microwave circuits, metamaterials, LH materials, antennas and their applications in wireless communications, and wireless power transmission. 